\title{
Prevalence of Extended-Spectrum Beta-Lactamases in Enterobacteriaceae, Pseudomonas and Stenotrophomonas as Determined by the VITEK 2 and E Test Systems in a Kuwait Teaching Hospital
}

\author{
Wafaa Jamal $^{\mathrm{a}}$ V.O. Rotimi ${ }^{\mathrm{a}-\mathrm{c}}$ Fatima Khodakhast $^{\mathrm{b}}$ Rolla Saleem $^{\mathrm{a}}$ \\ Aleyamma Pazhoor ${ }^{\mathrm{a}}$ Ghyada Al Hashim ${ }^{\mathrm{c}}$ \\ ${ }^{a}$ Division of Microbiology, Mubarak Al-Kabeer Hospital, and ${ }^{b}$ Department of Microbiology, Faculty of Medicine, \\ Kuwait University, and ${ }^{\mathrm{C}}$ Infection Control Unit, Mubarak Hospital, Kuwait
}

\section{Key Words}

Prevalence $\cdot$ Extended-spectrum $\beta$-lactamases ·

VITEK $2 \cdot$ E test

\begin{abstract}
Objective: To determine the prevalence of extendedspectrum $\beta$-lactamase (ESBL)-producing members of the Enterobacteriaceae using VITEK 2 and $E$ test systems. Materials and Methods: A total of 3,592 consecutive gram-negative isolates (single isolate per patient) of the family of Enterobacteriaceae and Pseudomonas adjudged to be clinically relevant to the patient's infection were studied for ESBL production over a period of 1 year at Mubarak Al-Kabeer Hospital, Kuwait. Two methods were used: the automated VITEK 2 system and E test $\mathrm{ESBL}$, a manually manipulated plastic strip containing various gradients of $\beta$-lactam antibiotics. These tests and interpretative criteria for the results were performed according to the manufacturer's instructions. Results: Of the 3,592 bacterial isolates, $264(7.5 \%)$ and $185(5.2 \%)$ were positive for ESBL production by the VITEK 2 and $E$
\end{abstract}

test, respectively. All the ESBL-producing Pseudomonas aeruginosa identified by VITEK 2 gave indeterminate results by $E$ test. Prevalent ESBL producers, identified by the VITEK 2 versus E test, respectively, were: Citrobacter spp. (15 vs. $3.2 \%)$, K. pneumoniae (12.2 vs. $11.4 \%)$, Enterobacter spp. (12 vs. $3 \%)$, E. coli $(6.5$ vs. $5.6 \%)$, P. aeruginosa (6.5 vs. $0 \%$ ) and Morganella spp. ( 2 vs. $1 \%$ ). The most common infection associated with ESBL-producing pathogens was urinary tract infection $(68.2 \%)$, followed by wound infection (14.4\%) and bloodstream infection (6.1\%). Conclusion: The result of this study showed a relatively high prevalence of clinically significant ESBL producers among the Enterobacteriaceae and Pseudomonas spp. at our teaching hospital. The VITEK 2 identified a higher prevalence of ESBL strains than the $E$ test.

\begin{tabular}{ll}
\hline KARGER & $\oplus$ 2005 S. Karger AG, Basel \\
Fax +41 61 306 12 34 & $1011-7571 / 05 / 0145-0325 \$ 22.00 / 0$ \\
$\begin{array}{l}\text { E-Mail karger@karger.ch } \\
\text { www.karger.com }\end{array}$ & $\begin{array}{l}\text { Accessible online at: } \\
\text { www.karger.com/mpp }\end{array}$
\end{tabular}




\section{Introduction}

A multitude of evidence in the literature has shown a worldwide increase in bacterial resistance to B-lactam antibiotics. Antibiotic resistance is complex and dynamic. This is because new factors, apart from the genetic and biochemical mechanisms already recognized, continue to be discovered. The spread of bacterial resistance to some important antibiotics commonly used in the hospital to treat infections, some life-threatening, is partly related to widespread dissemination of plasmid-mediated extended-spectrum B-lactamases (ESBLs). ESBLs are enzymes that have the ability to hydrolyze oxyimino-aminothiazolyl cephalosporins, e.g. cefuroxime, ceftazidime, cefotaxime, ceftriaxone and cefipime as well as penicillin, monobactam and other cephalosporins except cephamycins [1]. They are often seen in Klebsiella pneumoniae and Escherichia coli, especially in nosocomial infections in the intensive care units (ICU) and other specialized units such as oncology, burn, neonatal wards, and in infections produced by indwelling devices, and are rarer in other members of the Enterobacteriaceae [2]. Several ESBLs have also been found in Pseudomonas aeruginosa, but many of these are unusual types, not TEM and SHV variants [3, 4]. Unfortunately, these enzymes may not be easily detectable in the laboratory and thus lead to treatment failure with what may be deemed to be an appropriate therapy.

Infection with ESBL-producing bacteria is usually hospital-acquired, especially in the ICU settings as well as in nursing homes [5]. The common types of infection are urinary tract infection, peritonitis, and intra-abdominal sepsis. This is because the normal habitat of the Enterobacteriaceae is the gut from where the bacteria can easily reach these sites. However, they can colonize the upper respiratory tract and the skin of hospitalized patients, resulting in hospital-acquired pneumonia and central line-related bacteremia. In hospitalized patients who had undergone neurosurgical procedures, ESBL-producing organisms may cause meningitis. The major problems with these infections are the associated limitation of antibiotic therapeutic options, significantly longer hospital stays $[6,7]$, higher cost of management [7] and clinical failure [8]. These important problems make it prudent to be able to detect ESBLs in the clinical laboratory for optimal therapy and infection control intervention. The aim of the study was to compare the ability of VITEK 2 (bioMérieux, Marcy-l'Etoile, France) and E test (AB Biodisk, Solna, Sweden) in detecting ESBL production in multiresistant isolates of
Enterobacteriaceae and $P$. aeruginosa and to determine the prevalence of ESBL-producer strains in our hospital.

\section{Materials and Methods}

\section{Bacterial Isolates}

A total of 3,592 clinically significant bacterial strains belonging to the family Enterobacteriaceae, that were isolated from patients seen and treated at the Mubarak Al-Kabeer Hospital, Kuwait, between January and December 2003, were studied for ESBL production. The main criterion for selection of strains for comparative study was that they were consecutive isolates clinically relevant to patients' condition enough to warrant giving antibiotic therapy. Duplicate isolates from the same patient were not included in the study.

\section{VITEK 2 Analysis}

VITEK cards (ID-GNI) were used for identification of all gram-negative bacilli (GNB). Antimicrobial susceptibility test was done by using two types of VITEK cards: VITEK card AST-N022 for antimicrobial susceptibility of non-lactose-fermenting, oxidase-positive GNB, and AST-N020 for lactose-fermenting and non-lactose-fermenting, oxidase-negative GNB. They were inoculated according to the manufacturer's instruction. The results were interpreted by using software version VTK-R01.02, an advanced expert system (AES) [2, 9-11]. The AES is based on over 2,000 phenotypes and 20,000 MIC distributions, which have been derived from published literature, internal data generated at bioMérieux, and outside experts. Following the identification and antimicrobial susceptibility testing of the bacterial isolates, the AES software then searches for the MIC distributions in its knowledge base to ascertain if the result is consistent with any of the phenotypes established for a particular bacterium in order to establish a biological validation. This comparison allows the AES to determine if the identification is consistent with the susceptibility pattern and if the MICs are consistent with a specific phenotype. At the end of each run, a printout containing the MIC values of the antibiotics with ESBL status of each isolate was obtained and recorded.

\section{E Test ESBL}

Both cefotaxime/cefotaxime combined with clavulanic acid strip and ceftazidime/ceftazidime with clavulanic acid strip were used. E test ESBL was performed according to the manufacturer's instruction. Briefly, an overnight culture of the bacteria diluted to a $0.5 \mathrm{McF}$ arland turbidity standard was used to inoculate MuellerHinton agar plate (Oxoid, Basingstoke, UK). After drying, the E test strips were applied on the plates and incubated overnight at $37^{\circ} \mathrm{C}$. The MICs on both ends were read on the intersection of the inhibition ellipse and the E test-strip edge. E. coli ATCC 35218, which produces TEM-1-B-lactamase (non-ESBL), was used as negative control. ESBL-positive control strain of $K$. pneumoniae ATCC 700603 and a local strain of ESBL-positive $P$. aeruginosa, producing a VEB-1-like ESBL [4], were used as positive controls. They were tested with each run. 


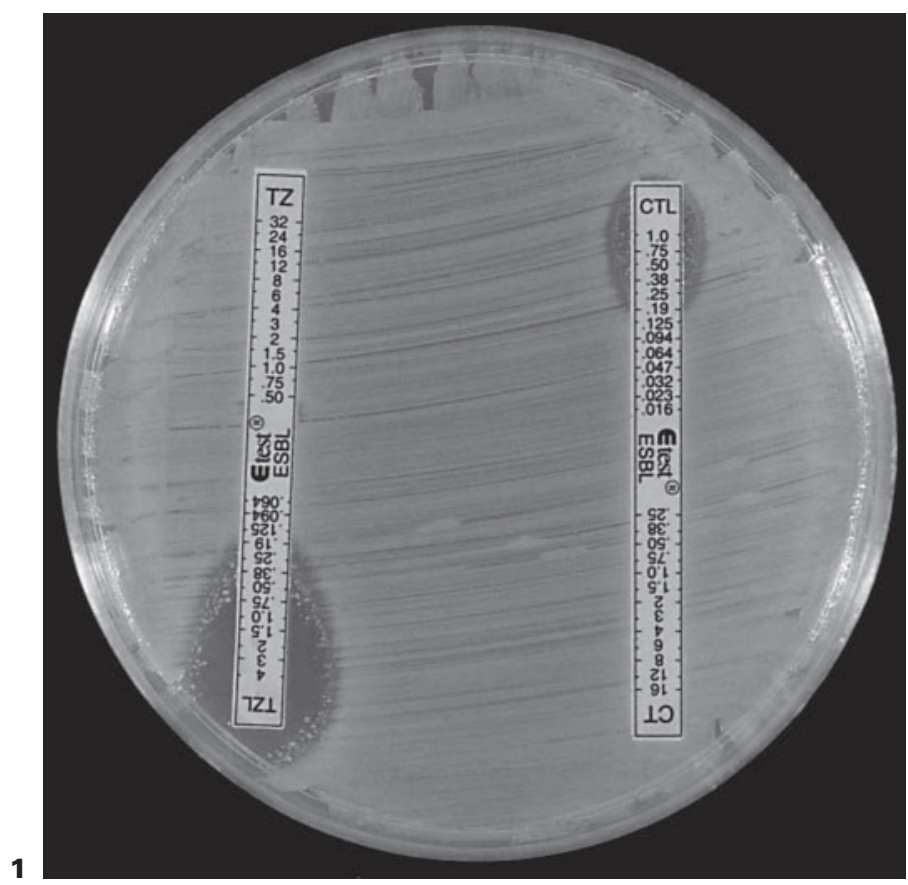

Fig. 1. A clear-cut E test ESBL positivity in E. coli showing MIC of $\mathrm{CT} / \mathrm{CTL}=16 / 0.23$, ratio $>8$ and $\mathrm{MIC}$ of $\mathrm{TZ} / \mathrm{TZL}=32 / 0.19$, ratio $>8$. $\mathrm{CT}=$ Cefotaxime; $\mathrm{CTL}=$ cefotaxime combined with clavulanic acid; $\mathrm{TZ}$ = ceftazidime; $\mathrm{TZL}=$ ceftazidime combined with clavulanic acid.

Fig. 2. a E test ESBL-positive isolate showing a rounded phantom inhibition zone below TZ and CT. The rounded phantom inhibition zone is indicative of ESBL production. $\mathbf{b} \mathrm{E}$ test ESBL production indicated by a deformation of the $\mathrm{CT}$ and $\mathrm{TZ}$ inhibition ellipse.

\section{Results}

The synergic activity of clavulanic acid (L) with both ceftazidime (TZ) and cefotaxime (CT) was confirmed by means of two different $\mathrm{E}$ test strips containing ceftazidime and cefotaxime with or without clavulanate. In accordance with the manufacturer's interpretative criteria,
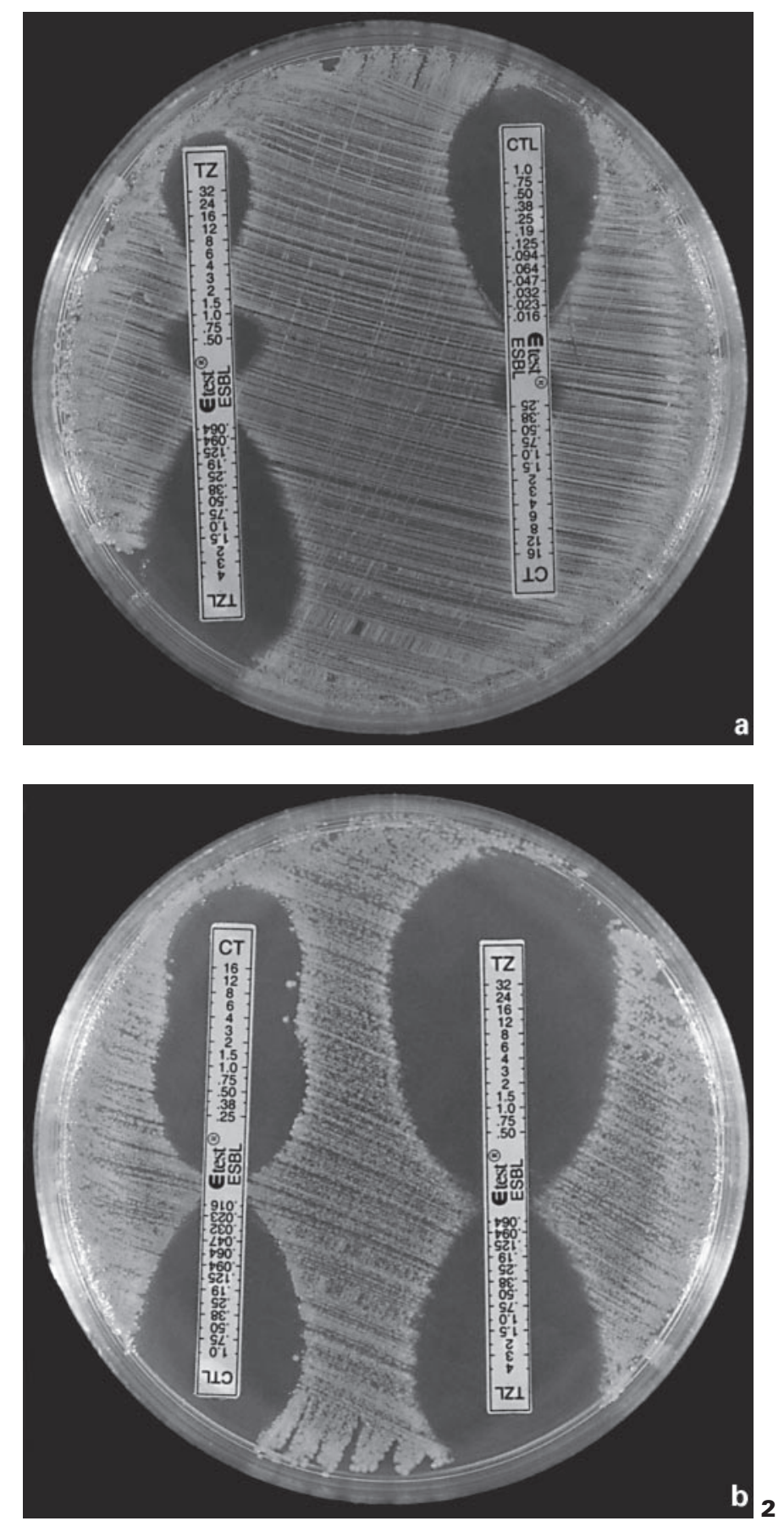

the presence of ESBL was confirmed when the MIC of either cefotaxime or ceftazidime is reduced by $\geq 3 \log _{2}$ dilutions in the presence of clavulanic acid. In other words, an isolate is considered as ESBL-positive when the MIC of TZ $\geq 1 \mu \mathrm{g} / \mathrm{ml}$ and the ratio of TZ/TZL $\geq 8 \mu \mathrm{g} / \mathrm{ml}$ or MIC of CT $\geq 0.5 \mu \mathrm{g} / \mathrm{ml}$ and the ratio of CT/CTL $\geq 8$ (fig. 1). In addition, a strain was considered ESBL-posi- 
Table 1. The prevalence of ESBL-producing bacterial isolates in Mubarak Hospital

\begin{tabular}{|c|c|c|c|}
\hline \multirow[t]{2}{*}{ Bacteria } & \multirow{2}{*}{$\begin{array}{l}\text { Total } \\
\text { number } \\
\text { of isolates }\end{array}$} & \multicolumn{2}{|c|}{$\begin{array}{l}\text { Number }(\%) \text { of } \\
\text { ESBL-positive isolates by }\end{array}$} \\
\hline & & E test & VITEK 2 \\
\hline E. coli & 2,107 & $119(5.6)$ & $137(6.5)$ \\
\hline P. aeruginosa & 536 & $0(0)$ & $35(6.5)$ \\
\hline K. pneumoniae & 509 & $58(11.4)$ & $62(12.2)$ \\
\hline Enterobacter spp. & 134 & $4(3.0)$ & $16(12)$ \\
\hline Proteus spp. & 93 & $1(1.1)$ & $1(1.1)$ \\
\hline Citrobacter spp. & 63 & $2(3.2)$ & $10(15.9)$ \\
\hline Morganella spp. & 50 & $1(2.0)$ & $2(4.0)$ \\
\hline Stenotrophomonas & 36 & $0(0)$ & $1(2.8)$ \\
\hline Total & 3,529 & $185(5.2)$ & $264(7.5)$ \\
\hline
\end{tabular}

tive if a phantom zone or a deformity of ceftazidime and cefotaxime zone could be observed independent of the ratios or MICs (fig. 2). The outcome of the result was indeterminate when both MICs were outside the test range of the test device or when the result of one strip was negative and the result of the other strip was indeterminate, for example, when the TZ/TZL ratio was $>32 />4$ (indeterminate) or CT/CTL was ESBL-negative $(6 />1)$ and $\mathrm{TZ} / \mathrm{TL}$ indeterminate.

The analysis of the data showed that there were discrepancies between VITEK 2 and E test detection of ESBLs. Of 3,529 clinically significant isolates, 264 (7.5\%) and 185 (5.2\%) were ESBL producers by VITEK 2 and $\mathrm{E}$ test, respectively. All those positive by the E test were also positive by the VITEK 2 system. The prevalence of ESBL-producing bacterial isolates is shown in table 1 . The prevalent ESBL producers identified by the VITEK 2 versus E test, respectively, were as follows: Citrobacter spp. (15.9 versus $3.2 \%$ of 63 isolates), $K$. pneumoniae (12.2 versus $11.4 \%$ of 509), Enterobacter spp. (12 versus $3 \%$ of 134$),$ E. coli (6.5 versus $5.6 \%$ of 2,107$)$, P. aeruginosa (6.5 versus $0 \%$ of 536), and Morganella spp. (4 versus $2 \%$ of 50 ).

The distribution of the 264 ESBL-positive isolates detected by the VITEK 2 according to source is shown in table 2. Those positive by the E test detection method were from the same sources as the VITEK 2. The most common infection that yielded ESBL-producing bacteria was urinary tract infections, accounting for $180(68.2 \%)$ out of 264. This was followed by wound infections, 38 $(14.4 \%)$, bacteremia, $16(6.1 \%)$, respiratory secretions, 16 (6.1\%), and others $13(4.9 \%)$, excluding 1 case of menin-
Table 2. Distribution of ESBL-positive isolates determined by VITEK 2 by source

\begin{tabular}{lrrrrr}
\hline Specimen & E. coli & $\begin{array}{l}\text { Kleb- } \\
\text { siella }\end{array}$ & $\begin{array}{l}\text { Pseudo- } \\
\text { monas }\end{array}$ & $\begin{array}{l}\text { Entero- } \\
\text { bacter }\end{array}$ & Others \\
\hline Urine & 103 & 43 & 14 & 12 & 8 \\
Blood & 6 & 7 & 2 & 1 & 0 \\
Wound & 18 & 6 & 9 & 2 & 3 \\
Cerebrospinal fluid & 1 & 0 & 0 & 0 & 0 \\
Respiratory secretions & 3 & 5 & 7 & 0 & 1 \\
Others & 6 & 1 & 3 & 1 & 2 \\
\hline Total & 137 & 62 & 35 & 16 & 14 \\
\hline
\end{tabular}

Table 3. Distribution of ESBL-positive isolates of Enterobacteriaceae determined by $\mathrm{E}$ test and VITEK 2

\begin{tabular}{|c|c|c|c|c|}
\hline \multirow[t]{2}{*}{ Bacterial isolate } & \multicolumn{3}{|l|}{ E test } & \multirow[t]{2}{*}{ VITEK 2} \\
\hline & positive & negative & $\begin{array}{l}\text { indeter- } \\
\text { minate }\end{array}$ & \\
\hline E. coli & 119 & 9 & 9 & 137 \\
\hline K. pneumoniae & 58 & 1 & 3 & 62 \\
\hline P. aeruginosa & 0 & 0 & 35 & 35 \\
\hline Enterobacter spp. & 4 & 0 & 12 & 16 \\
\hline Citrobacter spp. & 2 & 2 & 6 & 10 \\
\hline Others & 2 & 0 & 2 & 4 \\
\hline Total & 185 & 12 & 67 & 264 \\
\hline
\end{tabular}

gitis $(0.4 \%)$. The overall commonest ESBL producers were E. coli and $K$. pneumoniae, representing 137 (51.9\%) and $62(23.5 \%)$ of the 264 isolates, respectively. The majority of the blood isolates were $K$. pneumoniae $(7 / 16$; $43.8 \%)$ and $E$. coli $(6 / 16 ; 37.5)$. One of the ESBL-producing $E$. coli isolates was isolated from cerebrospinal fluid of the patient with meningitis. In patients with urinary tract infection, E. coli $(103 / 180 ; 57.2 \%)$ was the predominant ESBL producer, followed, in decreasing prevalence, by Klebsiella $(43 / 180 ; 23.9 \%)$, P. aeruginosa (14/180; 7.8\%) and Enterobacter spp. (12/180; 6.7\%).

The numbers of the ESBL-producing bacterial isolates detected by E test and VITEK 2 are shown in table 3. A total of $185(70.1 \%)$ isolates were positive by the E test; the remaining $67(25.4 \%)$ and $12(4.6 \%)$ were indeterminate and negative, respectively. All of the $P$. aeruginosa strains gave indeterminate results by $\mathrm{E}$ test, followed by 12 (17.9\%) of Enterobacter, 9 (13.4\%) of E. coli, 6 (9\%) of Citrobacter and 3 (4.5\%) of Klebsiella sp. 


\section{Discussion}

ESBLs have been found in a wide range of gram-negative bacteria; but the vast majority of strains producing these enzymes belong to the family Enterobacteriaceae. In many hospitals, $K$. pneumoniae remains the major ESBL producer [1]. However, E. coli is another important bacterium, which has a high representation among ESBL producers circulating in the hospital environment $[1,12,13]$. ESBL has also been detected in clinical isolates of Enterobacter cloacae and Enterobacter aerogenes [14]. Sporadic isolates of ESBL-producing Salmonella spp. or nosocomial outbreaks caused by these organisms have been identified in several countries in Latin America, Africa, Europe and Asia [15-18]. There are very scanty reports of non-Enterobacteriaceae ESBL producers, which are considered rare, with $P$. aeruginosa being the most important among them [3, 4]. The result of our present study shows that the frequency of ESBL producers in hospitals varies. In our hospital, the overall prevalence was $7.5 \%$. A recent study in Brooklyn, N.Y. showed that ESBLs were produced by $17.2 \%$ of selected members of the Enterobacteriaceae (K. pneumoniae, E. coli, and Proteus mirabilis) [19], in contrast to a wider French investigation, which revealed an overall prevalence of 3.2\% of ESBL-producing Enterobacteriaceae [20]. The prevalence rate in our hospital is similar to that in the report of a wide Italian survey obtained from 10 medical centers, which indicated that $6.3 \%$ of Enterobacteriaceae harbor ESBL genes [21]. In that Italian study, the prevalence of ESBL-positive $K$. pneumoniae, $E$. coli and $P$. mirabilis was $20,1.2$ and $16.3 \%$, respectively, which contrasts with our findings on these individual pathogens. The prevalence of ESBL-producing Klebsiella and Proteus was considerably lower and E. coli higher in our study compared to that of Spanu et al. [21]. A report from some institutions in the Netherlands indicated that the prevalence of these organisms producing ESBL was less than 1\% [22], while another, a multicenter ICU study in the same country, showed a contrasting higher prevalence of $16 \%$ for Klebsiella [23]. In this present study, the prevalence of ESBL-producing Enterobacter of $12 \%$ is almost a quarter of the $46 \%$ rate reported by Tzelepi et al. [14]. However, the prevalence of ESBL in our Citrobacter spp. was comparable to that found during an outbreak of Citrobacter freundii infections in Poland [24].

There is currently a great need for a reliable test to detect ESBLs in clinical isolates of Enterobacteriaceae. The test needs to be practically feasible for routine use in the clinical laboratory. E test, in our study, failed to detect all ESBL-positive $P$. aeruginosa and nearly 30\% of other gram-negative organisms in comparison to VITEK 2. Although some studies have demonstrated reliable results with E test [25-27], others did not [22, 23, 28]. Even Leverstein-van Hall et al. [27], who stated that $\mathrm{E}$ test gave an accurate result, reported that there were some limitations with the test, which included the indeterminate results in 5\% and inability to differentiate between chromosomal K1 (KOXY) hyperproduction and ESBLs. Our ESBL detection rate by E test of $70 \%$, using the same manufacturer's recommendations, is slightly discordant with the $81 \%$ rate obtained by Vercauteren et al. [23], a rate that increased to $88 \%$ when the recommendation of Cormican et al. [28] was adopted, using a breakpoint of 5 instead of 8 . It is noteworthy that our study recorded a $25.3 \%$ indeterminate result with $\mathrm{E}$ test and a false-negative result in $4.5 \%$. Some other limitations of the E test ESBL method include the fact that a well-trained and experienced technical staff is needed, at least for the interpretation at all times and introduction of additional guidelines for reading and interpretation, which may increase the burden of the test.

The advantage of using ceftazidime/ceftazidime plus clavulanate has been reported; Stobberingh et al. [22] found fewer false-positive results when using ceftazidime/ceftazidime plus clavulanic acid than with cefotaxime/cefotaxime plus clavulanic acid. No such disparity was found in our study. Although the E test is relatively easy to perform, it is, however, expensive and there is difficulty in reading the mutant colonies along the zone border and inside the inhibition zone. In addition, this test in our study missed detection of all ESBL strains of Pseudomonas and about $30 \%$ of other gram-negative organisms. Therefore, it may not be ideal for routine use in our clinical laboratory.

The VITEK 2 ESBL test, on the other hand, proved to be more reliable and easy to perform without any subjective interpretation of the results. It was able to detect ESBLs in clinical strains of E. coli, Klebsiella spp., Enterobacter spp., Citrobacter spp. as well as Pseudomonas spp. It is plausible that there is the possibility of false-positive results with the VITEK 2. However, with the addition of new ESBLs to the database used in developing the AES in the improved VITEK 2, the chances of recording false-positive results is considered low.

The high level of interest in developing tests for the detection of ESBL-producing Enterobacteriaceae under- 
scores the great need for such tests. Until such tests become available, many hospitals will continue to run the risk of missing some potentially problematic bacteria with consequent dissemination of resistant strains. Conceivably, patients will continue to be at risk of becoming infected with strains that will not respond to what appears to be an appropriate antibiotic therapy. Since patients most likely to become infected with ESBL-producing Enterobacteriaceae are those with prolonged hospital stays, such as patients in the ICU, and those who have invasive procedures, any delay in detection of this often hidden mechanism of resistance could have serious consequences $[29,30]$, including treatment failure $[8,30$, $31]$.

\section{Conclusion}

It is worthy of note to recognize the fact that there are more than 100 ESBLs known worldwide as of today. Since this is subject to rapid evolution and is involved in dynamic epidemiology [32], it is conceivable that the results of our study or any other study might not be applicable to all laboratories in other geographical locations throughout the world at this time, especially if the old VITEK 2 with limited ESBL database is used. This study showed a relatively high prevalence of clinically significant ESBL producers among the Enterobacteriaceae and $P$. aeruginosa and VITEK 2 appears to be superior to E test in detecting ESBL.

\section{References}

1 Livermore DM: Bacterial resistance: origin, epidemiology, and impact. Clin Infect Dis 2003;36(suppl 1):11-23.

2 Livermore DM: $\beta$-Lactamases in laboratory and clinical resistance. Clin Microbiol Rev 1995;8:557-584.

-3 Nordmann P, Guibert M: Extended-spectrum $\beta$-lactamases in Pseudomonas aeruginosa. $\mathrm{J}$ Antimicrob Chemother 1998;42:128-131.

-4 Poirel L, Rotimi VO, Mokaddas EM, Karim A, Nordmann P: VEB-1 like extended spectrum beta-lactamases in Pseudomonas aeruginosa, Kuwait. Emerg Infect Dis 2001;7:468-470.

5 Wiener J, Quinn JP, Bradford PA, Goering RV, Nathan C, Bush K, Weinstein RA: Multiple-antibiotic resistant Klebsiella and Escherichia coli in nursing homes. JAMA 1999;281: 517-523.

-6 Lautenbach E, Patel JB, Bilker WB, Edelstein PH, Fishman NO: Extended spectrum $\beta$-lactamase producing Escherichia coli and Klebsiella pneumoniae: risk factors for infection and impact of resistance on outcomes. Clin Infect Dis 2001;32:1162-1171.

-7 Schiappa DA, Hayden MK, Matushek MG, Hashemi FN, Sullivan J, Smith KY, Miyashiro D, Quinn JP, Weinstein RA, Trenholme GM: Ceftazidime-resistant Klebsiella pneumoniae and Escherichia coli bloodstream infection: a case-control and molecular epidemiologic investigation. J Infect Dis 1996;174:529-936.

8 Paterson DL, Ko W-C, Von Gottberg A, Casellas JM, Mulazimoglu L, Klugman KP, Bonomo RA, Rice LB, McCormack JG, Yu VL: Outcome of cephalosporin treatment for serious infections due to apparently susceptible organisms producing extended spectrum $\beta$-lactamases: implications for the clinical microbiology laboratory. J Clin Microbiol 2001;39: 2206-2212.

\section{Canton R, Perez-Vazquez M, Oliver A, Coque TM, Loza E, Ponz F, Baquero F: Validation of VITEK-2 and the Advanced Expert System with a collection of Enterobacteriaceae har- bouring extended spectrum or inhibitor resis- tant beta-lactamases. Diagn Microbiol Infect Dis 2001;41:65-70. \\ 10 Sanders CC, Peyret M, Moland ES, Shubert C, Thomson KS, Boeufgras JM, Sanders WE Jr: Ability of VITEK 2 Advanced Expert Sys- tem to identify beta-lactam phenotypes in iso- lates of Enterobacteriaceae and Pseudomonas aeruginosa. J Clin Microbiol 2000;38:570- 574.}

-11 Sanders CC, Peyret M, Moland ES, Cavalieri SJ, Shubert C, Thomson KS, Boeufgras JM, Sanders WE: Potential impact on VITEK 2 system and Advanced Expert System on the clinical laboratory of a university-based hospital. J Clin Microbiol 2001;39:2379-2385.

12 Bush K: Is it important to identify extendedspectrum beta-lactamase producing isolates? Eur J Clin Microbiol Infect Dis 1996;15:361364.

13 Hsueh PR, Liu YC, Yang D, Yan JJ, Wu TL, Huang WK, Wu JJ, Ko WC, Leu HS, Yu CR, Luh KT: Multicenter surveillance of antimicrobial resistance of major bacterial pathogens in intensive care units in 2000 in Taiwan. Microb Drug Resist 2001;7:373-382.

14 Tzelepi E, Giakkoupi P, Sofianou D, Loukova V, Kemeroglou A, Tsakris A: Detection of extended-spectrum $\beta$-lactamases in clinical isolates of Enterobacter cloacae and Enterobacter aerogenes. J Clin Microbiol 2000;38:542546.

15 Bradford PA, Yang Y, Sahm D, Grope I, Gardovska D, Storch G: CTX-M-5, a novel cefotaxime-hydrolyzing $\beta$-lactamase from an outbreak of Salmonella typhimurium in Latvia. Antimicrob Agents Chemother 1998;42:19801984.
6 Shannon K, French G: Multiple-antibiotic-resistant Salmonella. Lancet 1998;352:490.

-17 Tassios PT, Gazouli M, Tzelepi E, Milch H, Kozlova N, Sidorenko S, Legakis NJ, Tzouvelekis LS: Spread of Salmonella typhimurium clone resistant to expanded spectrum cephalosporins in three European countries. J Clin Microbiol 1999;37:3774-3777.

18 Mirza S, Kariuki S, Muman KZ, Beeching NJ, Hart CA: Analysis of plasmid and chromosomal DNA of multidrug resistant Salmonella enterica Serovar typhi from Asia. J Clin Microbiol 2000;38:1449-1452.

-19 Saurina G, Quale JM, Manikal VM, Oydna E, Landam D: Antimicrobial resistance in Enterobacteriaceae in Brooklyn, NY: epidemiology and relation to antibiotic usage patterns. J Antimicrob Chemother 2000;45:895-898.

20 De Champs C, Sirot D, Chanal C, Bonnet J: A 1998 survey of extended spectrum $\beta$-lactamases in Enterobacteriaeae in France: the French study Group. Antimicrob Agents Chemother 2000;44:3177-3179.

-21 Spanu T, Luzzaro F, Perilli M, Amicosante G, Toniolo A, Fadda G: The Italian ESBL Study Group: Occurrence of extended-spectrum $\beta$ lactamases in members of the family Enterobacteriaceae in Italy: implications for resistance to $\beta$-lactams and other antimicrobial drugs. Antimicrob Agents Chemother 2002; 46:196-202.

-22 Stobberingh EE, Arends J, HoogkampKorstanje JA, Goessens WH, Visser MR, Buiting AG, Debets-Ossenkopp YJ, van Ketel RJ, van Ogtrop ML, Sabbe LJ, Voorn GP, Winter HL, van Zeijl JH: Occurrence of extended spectrum beta-lactamases (ESBL) in Dutch hospitals. Infection 1999;27:348-354. 
-23 Vercauteren E, Descheemaeker P, Ieven M, Sanders CC, Goossens H: Comparison of screening methods for detection of extendedspectrum beta-lactamases and their prevalence among blood isolates of Escherichia coli and Klebsiella spp. in a Belgian teaching hospital. J Clin Microbiol 1997;35:2191-2197.

24 Palucha A, Mikiewicz B, Hryniewicz W, Gniadkowski M: Concurrent outbreaks of extended-spectrum $\beta$-lactamase-producing organisms of the family Enterobacteriaceae in a Warsaw hospital. J Antimicrob Chemother 1999;44:489-499.

25 Brown DFJ, Wattam Walpole E: Detection of extended spectrum beta lactamases (ESBLs) with E-test ESBL strip. Abstracts, 35th Intersci Conf on Antimicrob Agents and Chemother, American Society for Microbiology, Washington, 1995.
26 Harrel LJ, Thorpe JJ, McDonald LC, Reller LB: Analysis of suspected extended spectrum beta-lactamase (ESBL)-producing Klebsiella spp by the new E-test ESBL strip, double disk diffusion test and pulsed field electrophoresis (PFGE). Abstracts, 35th Intersci Conf on Antimicrob Agents and Chemother, Washington, 1995.

27 Leverstein-van Hall MA, Fluit AC, Paauw A, Box AT, Brisse S, Verhoef J: Evaluation of the Etest ESBL and the BD Phoenix, VITEK 1 and VITEK 2 automated instruments for detection of extended-spectrum beta-lactamases in multiresistant Escherichia coli and Klebsiella spp. J Clin Microbiol 2002;40:3703-3711.

28 Cormican MG, Marshall SA, Jones RN: Detection of extended-spectrum beta-lactamase (ESBL)-producing strains by $\mathrm{E}$ test ESBL screen. J Clin Microbiol 1996;34:1880-1884.
29 Meyer KS, Urban C, Eagan JA, Berger BJ, Rahal JJ: Nosocomial outbreak of Klebsiella infection resistant to late-generation cephalosporins. Ann Intern Med 1993;119:353-358.

30 Lucet JC, Chevret S, Decre D, Vanjak D, Macrez A, Bedos JP, Wolff M, Regnier B: Outbreak of multiply resistant Enterobacteriaceae in an intensive care unit: epidemiology and risk factors for acquisition. Clin Infect Dis 1996;22:430-436.

31 Karas JA, Pillay DG, Muckart D, Sturm AW: Treatment failure due to extended spectrum $\beta$-lactamase. J Antimicrob Chemother 1996; 37:203-204.

-32 Gniadkowski M: Evolution and epidemiology of extended-spectrum beta-lactamases (ESBLs) and ESBL-producing microorganisms. Clin Microbiol Infect 2001;7:597-608. 